\title{
Decomposition of LCD screen inverter by pyrolysis
}

\author{
Agnieszka Gurgul ${ }^{1,}$, , Włodzimierz Szczepaniak ${ }^{1}$, and Monika Zabłocka-Malicka ${ }^{2}$ \\ ${ }^{1}$ Wrocław University of Science and Technology, Faculty of Environmental Engineering, \\ Wybrzeże Wyspiańskiego 27, 50-370 Wrocław, Poland \\ ${ }^{2}$ Wrocław University of Science and Technology, Faculty of Chemistry, \\ Wybrzeże Wyspiańskiego 27, 50-370 Wrocław, Poland
}

\begin{abstract}
PCBs (Printed Circuit Boards) are important parts of electronic equipment and their use increases with technology development. Recycling of waste PCBs is challenging due to their complex structure and receives wide concerns as the amount of this type of waste is growing rapidly. In the article, the experiment of pyrolysis carried out with electronic waste sample was presented. The material employed in the present work was inverter of the LCD screen that it the example of the multilayer PCB. The correlation between pyrolysis temperature and gas emission from the system, which is associated with epoxy resin decomposition, is presented in the article.
\end{abstract}

\section{Introduction}

There is increasing concern about the volume of end-of-life electronics that is increasing due to technology development. Printed Circuit Boards (PCBs) are a common component of many electronic devices. A basic PCB consists of a flat sheet of insulating material and a layer of copper foil laminated to the substrate. A Printed Circuit Board can have multiple copper layers: a two-layer board has copper on both sides; multilayer boards have additional copper layers between layers of insulating material. FR-4 is the most common insulating substrate [1]. It is a composite material composed of fiberglass cloth with an epoxy resin binder that is flame resistant.

The treatment of waste PCBs is a challenging because of the diversity and complexity of materials and components [2]. General recycling routes include disassembly and materials recycling by mechanical processing, pyrometallurgy and hydrometallurgy or a combination of these techniques. Currently PCB waste are mostly recycled to recover metals that have the highest value. There were also research focused on recycling of non-metallic fraction from PCB [3]. Pyrolysis treatment has been studied as a method of recycling the synthetic polymers (also polymers mixed with fiberglass) [4]. Waste Printed Circuit Board pyrolysis has been investigated by a large number of researches [5]. Under vacuum or low pressure organic part of PCB decomposes to liquid and gaseous

\footnotetext{
*Corresponding author: agnieszka.gurgul@pwr.edu.pl
} 
phase that have potential to be used as fuel or chemical feedstock. In the solid residue, the metals are still contained and may be recovered by further chemical, pyrometallurgical or mechanical processes.

In the present study pyrolysis experiment of waste PCB has been investigated with the focus on determining correlation between pyrolysis temperature and the rate of gas emission from the system.

\section{Materials and methods}

\subsection{Multilayer Printed Circuit Board}

Pyrolysis of Printed Circuit Board was carried out with original LCD screen inverter sample. This material is an example of multilayer PCB bonded with epoxy resin that is characterized by a small amount of built-in components. The mass of a single inverter is about $5.85 \mathrm{~g}$. In the experiment 13 inverters with a total mass of $76.11 \mathrm{~g}$ were pyrolyzed. Figure 1 shows the original sample of PCB.

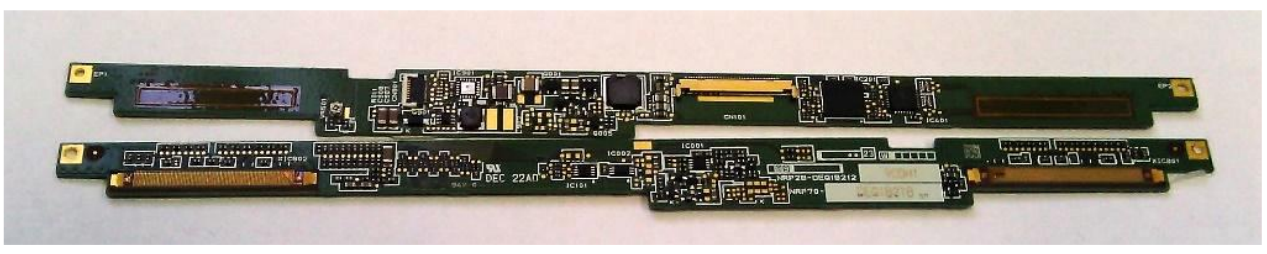

Fig. 1. Sample of PCB (inverter) before thermal treatment (both sides view).

Flame retardant FR-4 is a laminate material that consists of copper foil reinforced with fiberglass and bonded by epoxy resin binder that is flame resistant. Because of good mechanical values and insulating qualities this type of laminate found application in variety of electrical and electronic devices.

\subsection{Reactor}

The process of pyrolysis was carried out in the quartz tube reactor with an inner diameter of $36 \mathrm{~mm}$ and length of $1200 \mathrm{~mm}$, heated by four tube furnaces in four zones: $a$ - conversion of gasses, $b$, and $c$ - pyrolysis of waste sample zone, $d$-gas supply (Fig. 2). A detailed description of the system can be found elsewhere [6].

argon

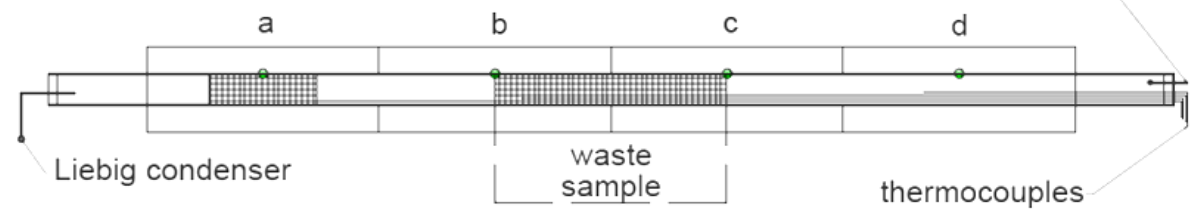

Fig. 2. Quartz reactor used in pyrolysis of PCB. 
Temperatures in the specified zones of the reactor were measured with four K-type thermocouples and registered with digital recorder APAR AR 206/8 (Poland). Furnaces heating the reactor were individually powered by electronic controllers RE31 or RE15 with SSR units (LUMEL S.A., Poland). The carrier gas used was argon (AirProducts, 99.999\% purity), which was injected into the system at $0.26 \mathrm{dm}^{3} / \mathrm{min}$ (velocity measured by rotameter). Gasses from the process were cooled down in the Liebig condenser and then washed with $0.10 \mathrm{M} \mathrm{NaOH}$. Variation of the gas flow due to pyrolysis was recorded with a TEST-THERM, TSI 4000/4000 flowmeter).

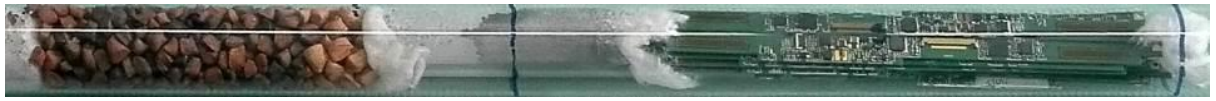

Fig. 3. Samples of inverters in quarts reactor before thermal processing.

The filled reactor (Fig. 3) was placed horizontally in tube furnaces and connected with other elements of the system. Then reactor was heated overnight before planned experiments and kept at $100^{\circ} \mathrm{C}$. Experiments started with heating of zone $a$ (conversion) and $d$ (gas supply) with increasing $20^{\circ} \mathrm{C} / \mathrm{min}$ until both zones achieved temperature of $500^{\circ} \mathrm{C}$. At this moment supply of argon to reactor had been started as well as heating of zone $b$ and $c$ with velocity $3^{\circ} \mathrm{C} / \mathrm{min}$. When zones with waste samples reached temperature of $850^{\circ} \mathrm{C}$ this temperature was maintained for 2 hours. After the end of the processes the furnaces were cooled at $20^{\circ} \mathrm{C} / \mathrm{min}$ to reach a temperature of about $100^{\circ} \mathrm{C}$. Subsequently, the Liebig condenser and gas supply pipe were disconnected from the system and disassembly started. During disassembly and emptying the reactor cooled down to the room temperature. Temperatures in the 4 zones were measured during the whole pyrolysis procesevery 30 seconds together with cooling stage which equals to 478 minutes.

\section{Results}

The solid residue after the pyrolysis process retained the structure of the original element but individual inverters were fragile and were easily broken into smaller parts. Elements built on the surface of inverters mostly detached from the PCB and formed a loose fraction. The surface of processed inverters had a black, glassy coating - Fig. 4. The mass of inverters after the process was $70.09 \mathrm{~g}$, which corresponds to a weight loss of $7.91 \%$ [6].

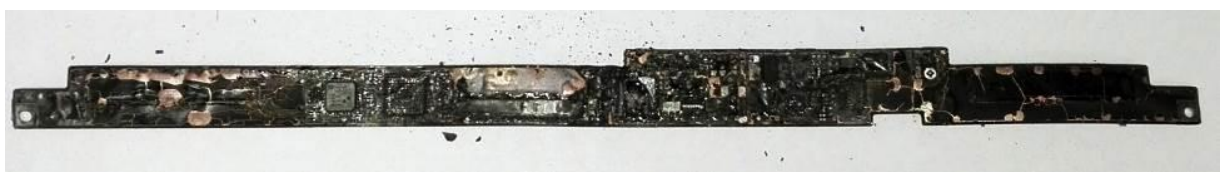

Fig. 4. Inverter sample after pyrolysis process.

After the process, the inner walls of the reactor were covered with dark deposits with a metallic luster. The liquid condensate formed in the pyrolysis process, weighing $1.00 \mathrm{~g}$, had a dark brown color and thick consistency (details of a typical characteristics of the oils from PCB pyrolysis may be found elsewhere [7]).

According to research [8] decomposition of epoxy resins in PCB depends directly on the process temperature. Decomposition of organic compound of laminate results in emission of the pyrolytic gas that is rich in $\mathrm{CO}, \mathrm{CO}_{2}, \mathrm{H}_{2}, \mathrm{CH}_{4}, \mathrm{Cl}-\mathrm{C} 4$ [9]. To observe the process of $\mathrm{PCB}$ degradation the temperature inside reactor and the emission rate of gas 
were measured. The results are presented in Fig. 5 as a correlation between the intensity of gas emission and the temperature measured in the zone $b$ of the reactor (Fig. 2) in the function of time.

It was not possible to calibrate the flowmeter on the producer gas, therefore the flowmeter signal intensity in arbitrary units [A.U.] was used in the process analysis. The highest flow of the pyrolytic gas was observed in the temperature range $200-300^{\circ} \mathrm{C}$, with maximum peak $\left(\mathrm{P}_{\mathrm{a}}\right)$ at $240^{\circ} \mathrm{C}$ (points $\mathrm{a}_{1}, \mathrm{a}_{2}$, Fig. 5). Many thermogravimetric researches on the PCB pyrolysis have been presented in literature. The authors found that resins in waste $\mathrm{PCB}$ decompose intensively in the temperature range of $300-400^{\circ} \mathrm{C}$. Below $300^{\circ} \mathrm{C}$ mass loss of the PCB sample is rather negligible, however above $400^{\circ} \mathrm{C}$ gradual and relatively small mass loss is also observed [10-15]. For inverter PCB sample investigated in this paper, intensive increase of the gas flow which may be related to the decomposition started at lower temperature, somewhat above $200^{\circ} \mathrm{C}$. The gas emission ended approximately at $360-370^{\circ} \mathrm{C}$. The difference between literature data and result of presented here investigation may be ascribed much slower heating $\left(3^{\circ} \mathrm{C} / \mathrm{min}\right.$ vs. $10-30^{\circ} \mathrm{C} / \mathrm{min}$ in literature), registration of the gas flow contrary to the weight decrease measurement and, maybe in the first place, specificity of the investigated sample of identical items.

In the research presented here, there was also observed the second, broad peak $\left(\mathrm{P}_{\mathrm{b}}\right)$ of gas emission, in the temperature range $600-750^{\circ} \mathrm{C}$. Points $\mathrm{b}_{1}$ (temperature) and $\mathrm{b}_{2}$ (gas emission) may be found in Fig. 5 in the middle part of peak, at temperature approximately $720^{\circ} \mathrm{C}$. The peak $\left(\mathrm{P}_{\mathrm{b}}\right)$ is not only lower but also smaller - the peaks' surfaces areas proportion $\mathrm{P}_{\mathrm{a}} / \mathrm{P}_{\mathrm{b}}$ is approximately $\approx 1.8$.

Carbonaceous residue is present in solid product after PCB pyrolysis. It may act as the reducer according to Boudouard reaction (1), which generates carbon monoxide - the reducer for potentially present oxides of metals (2). As the result, the mixture of carbon mono- and dioxide may increase output gas emission that is observed in the second peak (Fig. 5).

$$
\begin{gathered}
\mathrm{C}+\mathrm{CO}_{2}=2 \mathrm{CO} \\
\mathrm{MeO}+\mathrm{CO}=\mathrm{Me}+\mathrm{CO}_{2}
\end{gathered}
$$

There are another possible mechanisms of gas emission at high temperatures decomposition of carbonates (3) or reduction of sulfates (4). $\mathrm{CaCO}_{3}$, with equilibrium partial pressure of $\mathrm{CO}_{2}$ increasing from $1.5 \cdot 10^{-5}$ to 0.25 bar in the temperature range $500-800^{\circ} \mathrm{C}$, and $\mathrm{BaSO}_{4}$ with equilibrium constant of reaction (4) increasing from $4.5 \cdot 10^{-15}$ to $8.4 \cdot 10^{-6}$ in the same temperature range (assuming $\mathrm{p}_{\mathrm{CO}}=\mathrm{p}_{\mathrm{SO}_{2}}, \mathrm{p}_{\mathrm{CO}}+\mathrm{p}_{\mathrm{SO}_{2}}=1.4 \cdot 10^{-7}$ and $5.8 \cdot 10^{-3}$ bar, respectively), are the examples. Both are used as fillers in some plastics.

$$
\begin{aligned}
\mathrm{MeCO}_{3} & =\mathrm{MeO}+\mathrm{CO}_{2} \\
\mathrm{MeSO}_{4}+\mathrm{C} & =\mathrm{MeO}+\mathrm{SO}_{2}+\mathrm{CO}
\end{aligned}
$$




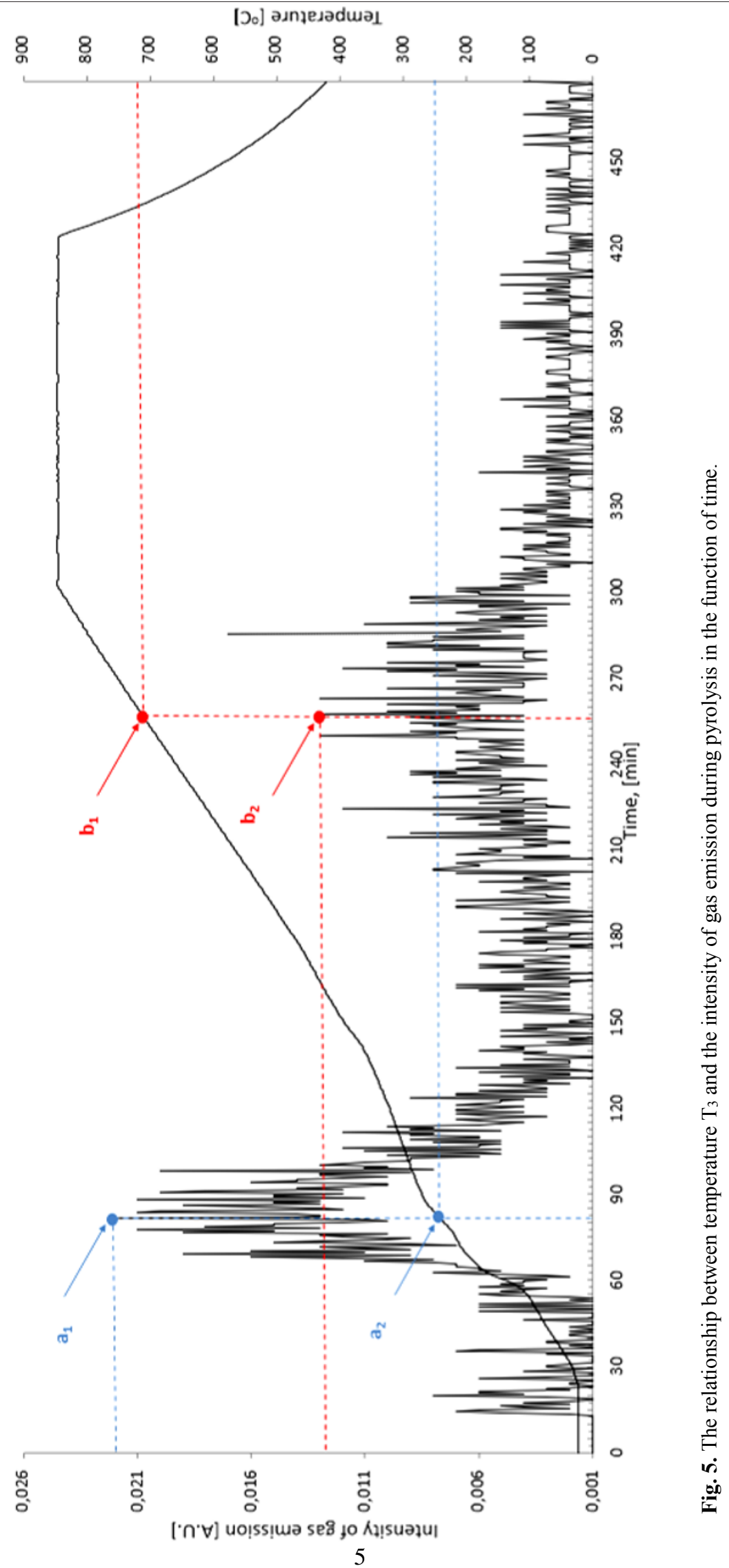




\section{Summary}

The rate of gas emission in thermal degradation of electronic waste - the sample of inverters, was investigated. It was noticed that gas emission proceeded in two ranges of temperatures: $200-300^{\circ} \mathrm{C}$ with maximum at $240^{\circ} \mathrm{C}$, and $600-750^{\circ} \mathrm{C}$ with maximum at $720^{\circ} \mathrm{C}$. Emission of the gas at higher temperatures could be related to, for example, metal oxides and sulfates reduction, or decomposition of carbonates.

\section{References}

1. A. Khan, R. Nema, International Journal of Computer Applications 55, 14 (2012)

2. K. Huang, J. Guo, Z. Xu, J. Hazard Mater. 164, 399-408 (2009)

3. J. Guo, J. Guo, Z. Xu, J. Hazard Mater. 168, 567-590 (2009)

4. S. R. Naqvi, H. M. Prabhakara, E. A. Bramer, W. Dierkes, R. Akkerman, G. Brema, Resourc. Conserv. Recy. 136, 118-129 (2018)

5. P. Hadi, M. Xua, C. S. K Lin, C. Hui, G. McKay, Journal of Hazardous Materials 283, 234-243 (2015)

6. A. Gurgul, W. Szczepaniak, M. Zabłocka-Malicka, Science of the Total Environment 624, 1119-1124 (2018)

7. Z. Ye, F. Yang, Y. Qiu, W. Lin, S. Sun, Process Safety and Environmental Protection 116, 654-662 (2018)

8. P. Evangelopoulos, E. Kantarelis, W. Yang, J. Anal. Appl. Pyrolysis 115, 337-340 (2015)

9. G. Jie, L. Shun, L. Mai-Xi, J. Anal. Appl. Pyrolysis 83, 185-189 (2008)

10. J. Li, H. Duan, K. Yu, L. Liu, S. Wang, Resourc. Conserv. Recy. 54, 810-815 (2010)

11. E. Kowalska, J. Radomska, P. Konarski, R. Diduszko, J. Oszczudowski, T. Opaliska, M. Więch, Z. Duszyc, J. Therm. Anal. Calorim. 86, 137-140 (2006)

12. Y. Shen, X. Chen, X. Ge, M. Chen, Journal of Environmental Management 214, 94-103 (2018)

13. S. Kumagai, G. Grause, T. Kameda, T. Yoshioka, J. Mater Cycles Waste Manag. 19, 282-293 (2017)

14. C. Quan, A. Li, N. Gao, J. Therm. Anal. Calorim. 110, 1463-1470 (2012)

15. P. Evangelopoulos, E.Kantarelis, W. Yang, Journal of Analytical and Applied Pyrolysis 115, 337-343 (2015) 